기후변화 등 잠재적 영향을 고려한 수중 미량오염물질의 관리방향 연구

\author{
김호정 · 홍용석* · 안종호 \\ 한국환경정책.평가연구원 물환경연구실 \\ 122-706 서울시 은평구 진흥로 215 \\ *고려대학교 환경기술정책협동과정, 환경시스템공학과 \\ 339-700 세종특별자치시 세종로 2511 \\ (2013년 8월 1일 접수, 2013년 10월 9일 수정본 접수, 2013년 10월 14일 채택)
}

\title{
A Study on the Management of Micropollutants in Water System Considering Climate Change and other Potential Effects
}

\author{
Hojeong Kim ${ }^{\dagger}$, Yongsuk Hong* and Jong Ho Ahn \\ Division of Water Environment, Korea Environment Institute (KEI), 215 Jinheungno, Eunpyeong-gu, Seoul 122-706, Korea \\ *Program in Environmental Technology and Policy, Department of Environmental Engineering, Korea University, \\ 2511 Sejong-ro, Sejong City 339-700, Korea
}

(Received 1 August 2013; Received in revised form 9 October 2013; accepted 14 October 2013)

요 약

본 논문에서는 국내·외 미량오염물질의 관리현황을 분석하고, 기후변화 등 수질관리에 영향을 주는 잠재적인 요소 를 고려한 미량오염물질의 관리방향을 제시하고자 하였다. 국내에서는 먹는 물 안전성 확보를 위해 수돗물 정수 및 원 수를 대상으로 미량오염물질에 대한 실태조사가 꾸준히 진행되었다. 근래에 들어 하천 · 호소수 중의 미량오염물질에 대해서도 조사가 진행되고 있으나 조사 항목과 횟수가 많지 않아 전체적인 미량오염물질 발생 및 검출 현황을 파악하 기에는 어려움이 있었다. 선진국에서는 미량오염물질의 실태조사 외에도 환경 매체에서의 거동, 인체 및 생태위해성, 처리공정 등에 미량오염물질 관리 전반에 대한 연구가 수행되고 있음을 확인할 수 있었다. 향후 기후변화에 따른 기온 과 수온의 상승, 수문학적인 순환의 변화 등으로 미량오염물질의 잔류 농도가 증가할 우려가 있다. 또한 물 재이용이 확대되는 과정에서 미량오염물질에 대한 우려가 커질 수 있다. 그러므로 먹는 물 또는 신체와 접촉하는 용도의 용수에 대해서는 사전예방의 관점에서 미량오염물질의 관리를 강화하는 것이 필요하다. 지표수 중의 미량오염물질에 대해서 는, 물환경 정책목표 중의 하나인 생태 위해성 관리의 관점에서, 물질의 거동, 생태 위해성 평가, 하 - 폐수처리공정에 서의 제어방안 등에 대한 연구가 확대되어야 할 것이다.

\begin{abstract}
In this study, the management polices of micropollutants (MPs) were reviewed and the future management strategy was discussed considering climate change and etc. In Korea, the investigation of drinking water has been actively carried out for the priority contaminants as well as MPs. Recently river and lake waters have been also examined for MPs. However, the coverage and depth of the investigation is limited. Moreover, climate change is likely to increase air \& water temperature and it will affect the hydrological cycle. Such changes may increase the residual concentrations of MPs in water system. As water reuse increases, the residual MPs of the recycled water may create public concerns. Thus, in a viewpoint of the precautionary principle, more stringent management of MPs is recommended for the drinking water and the body-contact water use. For the surface water, more studies are necessary to understand the ecological risk by MPs.
\end{abstract}

Key words: Drinking Water, Disinfection by-products, Micropollutants, Pharmaceuticals, Environmental Policy, Water Reuse

\section{1. 서 론}

2004년을 기준으로 단백질과 핵산을 제외한 2천 3백만 종의 유·무 기화합물이 CAS Registry에 등록되어 있으며, 이 중 $1 / 3$ 가량인 7 백

\footnotetext{
${ }^{\dagger}$ To whom correspondence should be addressed.

E-mail: tingker@kei.re.kr

\$이 논문은 KAIST 양지원 교수님의 정년을 기념하여 투고되었습니다.
}

만 종의 화합물이 상업적으로 이용된다. 이 중에서 각국 정부가 오 염물질 목록을 작성하거나 규제를 하는 물질은 23 만 종밖에 되지 않 는다[1]. 따라서 화학물질 관리는 잔류성, 생물농축성 및 독성이 높 아 위해성이 큰 화학물질을 중심으로 이루어졌다. 그러나 미국에서 만 매년 700개의 새로운 화학물질이 시장에 나오는 등 잠재적인 새 로운 오염물질이 계속 증가하고 있으며[2], 분석기술의 발달로 $\mathrm{ng} / \mathrm{L}$ 수준까지 일상적인 분석이 가능해짐에 따라 과거에는 검출되지 않았 
던 미량의 화학물질이 환경 매체에서 검출되는 사례가 증가하고 있다. 이에 따라수질관리 측면에서도 내분비계 장애물질(endocrine disrupting chemicals, EDCs), 의약물질 및 개인관리용품(pharmaceuticals and personal care products, PPCPs) 등 기존 규제대상에 포함되지 않은 물질들이 하수처리장 방류수 등에서 광범위하게 검출되며, 경우에 따라 정수처리를 거친 후에도 잔류하기도 한다. 그 결과 이러한 미 량의 새로운 오염물질에 대한 시민, 수도사업자, 정부의 우려가 빠르 게 커지고 있다[3].

본 논문에서 다루고자 하는 미량오염물질(micropollutant)이란 수 중에 $\mathrm{ng} / \mathrm{L} \sim \mu \mathrm{g} / \mathrm{L}$ 수준의 미량으로 존재하는 잠재적인 오염물질로 현 재 지표수/지하수 또는 먹는 물 환경기준 항목에서 제외되어 있는 항 목을 가리킨다. 전술하였듯이 미량오염물질은 새로운 화학물질의 개 발 - 이용과 분석기술의 발달로 근래에 들어 새롭게 조명을 받고 있 기 때문에 신규오염물질(emerging pollutant)로 불리기도 한다. 미량 오염물질은 중금속, 맹독성 농약 등 기존 관리대상 화학물질과 비교 할 때 (1) 규제기준이나 가이드라인이 없으며, (2) 독성과 위해성 정 보가 불충분하거나 제한되어 있으며, (3) 발생원, 이동 경로, 검출한 계 등이 매우 다른 특징을 가진다[4]. 미량오염물질의 독성 및 위해 성 정보가 부족하기 때문에 배출허용기준 등 규제기준을 설정하는 것이 쉽지 않다. 발생원, 이동경로, 검출한계가 일반적인 수질오염물 질과 다르다는 점은 수질측정망 운영, 배출원 규제 등 등 현행 수질 관리 제도의 적용에 한계가 있다는 것을 의미한다.

따라서 미량오염물질의 관리를 위해서는 기존의 수질관리와는 다 른 방향의 접근이 필요하며, 관리방향을 설정함에 있어 기후변화를 비롯한 잠재적인 수질영향 인자들이 함께 검토되어야 한다. 이에 본 논 문에서는 국내 수중 미량오염물질 관리제도, 검출현황 등 관리 현황을 분석하고, 해외 사례 등을 검토하여, 기후변화 등 잠재적인 영향에 대비 할 수 있는 미량오염물질 관리제도 개선방안을 제시하고자 하였다.

\section{2. 국내·외 미량오염물질 관리제도}

\section{2-1. 국내 관련 계획 및 조사사업}

\section{2-1-1. 「물환경관리 기본계획」}

수질 및 수생태 보전을 위한 국가 최상위 계획인「물환경관리 기 본계획: 4대강 대권역 수질보전 기본계획(2006 2015)」은 위해성과 생태계 건강성을 종합적으로 관리하는 것을 정책방향으로 설정하고 있으며 미량유해물질까지 위해성 관리 범위를 확대하는 것을 주요과 제로 제시하고 있다[5]. 특히 낙동강 유역처럼 수계 상-하류에 걸쳐 산업단지가 입지해 있는 지역에서는 미량의 화학물질까지 위해성 평 가 및 관리의 범위를 확대하는 것이 필요하다. 그 구체적인 방안으 로 유해화학물질의 사용량 증가에 발맞춰 특정수질유해물질 관리대 상 항목을 확대하며, 이들 물질에 대해 지정 및 배출허용기준을 마 련할 수 있는 체계를 확립할 계획이다. 수질환경기준 항목, 먹는 물 수질기준 항목, 유해물질 사용량 등의 정보를 토대로 미량유해화학 물질에 대한 조사목록을 작성하여 연차별로 모니터링을 실시할 계획 이다. 그리고 분석기술의 발전 수준을 고려하여 특정수질유해물질의 검출한계를 강화하여 미량오염물질의 측정·분석이 가능하도록 공정 시험방법을 개정하고 분석 장비 등을 현대화할 계획이다[5].

2-1-2. 환경기초조사사업

4대강 수계별로 수계관리기금을 지원을 받아 수계 전반에 대한 환
경기초조사사업이 진행 중에 있으며, 미량오염물질에 대한 모니터링 도 수행된다. 낙동강수계관리위원회의 환경기초조사사업을 예로 들 면, 「산업폐수의 미량 유해물질 최적 관리방안에 관한 연구(2005)」, 「상수원수의 안전성 및 유해성 평가(2006)」, 「낙동강수계 잠정관 리 유해물질 실태조사 및 예측시스템 개발(2008)」 등 조사·연구사 업의 형태로 미량오염물질에 대한 모니터링 및 위해도 평가 연구가 진행되었다[6-8]. 환경기초조사사업은 2007년부터 2015년까지 3단 계로 구성되어 있다. 1단계(2007 2009년)에서는 산업폐수 등을 대 상으로 관리대상 유해물질을 선별하고 위해성 평가를 위한 $\mathrm{DB}$ 를 구 축하는 연구가 진행되었으며, 2단계(2010 2012년)에서는 1단계 연 구결과에 따라 선정된 잠정관리 유해물질에 대한 실태조사가 지속되 었다. 3단계(2013 2015년)에서는 잠정관리 유해물질의 생태독성 및 위해성 평가가 진행될 계획이며 오염원이 입지한 지천에 대한 유해 물질 실태조사도 추진될 예정이다[9].

환경기초조사사업 등 2000년대 중·후반부터 미량오염물질의 조사 연구가 확대되고 있으며, 특히 이들 연구에서는 분석의 정도보증 (quality assurance, $\mathrm{QA}$ ) 및 정도관리(quality control, QC)에 대한 사 항이 중요하게 다뤄지고 있다. 미량오염물질은 일반적인 오염물질에 비해 자연계에서 낮은 농도로 존재하기 때문에, 분석의 $\mathrm{QA} / \mathrm{QC}$ 가 중 요하게 취급된다는 것은 조사 자료의 해석과 정확한 판단에 도움이 될 것으로 판단된다.

\section{2-1-3. 「먹는물 수질감시항목 운영지침」}

하천·호소 등 물환경 관리뿐 아니라 수돗물 수질관리 차원에서도 미량오염물질에 대한 관리가 이루어지고 있다. 먹는 물 수질기준에 등재되어 있지 않은 항목에 대해서도 먹는 물의 안전성을 확보하고 향후 수질기준 설정을 위해 필요한 자료를 확보하기 위해 관리가 필 요한 물질을 감시항목으로 지정하여 정기적인 모니터링을 진행하고 있다. 감시항목의 관리에 대한 제반사항은 환경부의 「먹는물 수질 감시항목 운영지침」에 규정되어 있다[10]. 시설규모 5 만 $\mathrm{m}^{3} / \mathrm{day}$ 이 상 정수장 등 일정 규모 이상의 수돗물을 생산·공급하는 수도사업자 는 위의 지침에 따라 정수(수돗물)와 원수(상수원수)를 대상으로 감 시항목을 측정하여 그 결과를 환경부와 국립환경과학원에 보고해야 한다. 상수원수에 대해서는 우라늄, 부식성 지수(Langelier index) 그 리고 조류독소인 microcystin-LR에 대해 조사를 실시한다, 우라늄 조 사주기는 처음연도 이후에는 검출결과에 따라 검사주기를 조정할 수 있으며, 조류독소는 클로로필 농도 및 남조류 세포수에 따라 주 1 3 회로 검사 주기를 달리한다[10]. 정수장에서 생산한 정수는 Table 1 과 같이 총 27 개 항목에 대해 모니터링이 진행된다. 감시항목의 분 석결과를 토대로 관계전문가의 검토 및 해외 기준과의 비교·검토를 통해 감시항목별로 모니터링을 지속할지 또는 먹는 물 수질기준으로 설정할지의 여부를 결정하게 된다.

\section{2-1-4. 수돗물 유해물질 실태조사}

환경부(국립환경과학원)는 위에서 설명한 수질감시항목을 비롯해 수돗물에 존재할 것으로 우려되는 오염물질에 대한 실태조사를 매년 실시하고 있다. 전년도 수돗물 조사 결과와 하천·호소수 오염물질 검 출결과 등을 토대로 조사대상 오염물질을 선정하며, 미량오염물질 또한 중요한 고려 대상이다. 2008년을 예로 들면, 수질 감시항목으 로 지정된 21 개 물질과, 12 개의 수질감시 후보항목, 31 개의 연차별 조차항목, 그리고 잔류의약물질인 Enrofloxacin을 비롯해 6개의 신 
Table 1. The examination frequency of drinking water surveillance substances [10]

\begin{tabular}{|c|c|c|c|c|c|}
\hline \multirow{2}{*}{ Categories } & \multirow{2}{*}{ Substances } & \multirow{2}{*}{ Guideline $(\mu \mathrm{g} / \mathrm{L})$} & \multicolumn{3}{|c|}{ Examination frequency } \\
\hline & & & Monthly & Quarterly & Yearly \\
\hline \multirow{2}{*}{ Hazardous inorganics } & Antimony & 20 & & & $\mathrm{~V}$ \\
\hline & Perchlorate & 15 & & $\mathrm{v}$ & \\
\hline \multirow{13}{*}{ Hazardous organics } & Vinyl Chloride & 2 & & & $\sqrt{ }$ \\
\hline & Styrene & 20 & & & $\sqrt{ }$ \\
\hline & Chloroethane & None & & $\sqrt{ }$ & \\
\hline & Bromoform & 100 & & $\sqrt{ }$ & \\
\hline & Chlorophenol & 200 & & & $\sqrt{ }$ \\
\hline & 2,4-Dichlorophenol & 150 & & & $\sqrt{ }$ \\
\hline & Pentachlorophenol & 9 & & & $\sqrt{ }$ \\
\hline & 2,4,6-Trichlorophenol & 15 & & & $\sqrt{ }$ \\
\hline & Di-2(ethylhexyl)phthalate & 80 & & & $\sqrt{ }$ \\
\hline & Di-2(ethylhexyl)adipate & 400 & & & $\sqrt{ }$ \\
\hline & Microcystin-LR & 1 & & 1-3 times a week & \\
\hline & $2,4-\mathrm{D}$ & 30 & & & $\sqrt{ }$ \\
\hline & Alachlor & 20 & & & $\sqrt{ }$ \\
\hline \multirow{7}{*}{ Disinfection by-products } & Bromate & 10 & & $\sqrt{ }$ & \\
\hline & Chlorate & 700 & & $\sqrt{ }$ & \\
\hline & Ethylendibromide & 0.4 & & & $\sqrt{ }$ \\
\hline & Bromochloroacetonitrile & None & & $\sqrt{ }$ & \\
\hline & Monobromoacetic acid & $60\left(\mathrm{HAAs}^{\dagger}\right)$ & & $\sqrt{ }$ & \\
\hline & Monochloroacetic acid & 60 (HAAs $\left.^{\dagger}\right)$ & & $\sqrt{ }$ & \\
\hline & Formaldehyde & 500 & & $\sqrt{ }$ & \\
\hline \multirow{3}{*}{ Aesthetic compounds } & Geosmin & 0.02 & $\sqrt{ }$ & & \\
\hline & 2-MIB(2-Methyl isoborneol) & 0.02 & $\sqrt{ }$ & & \\
\hline & Corrosion index (LI) & - & & $\sqrt{ }$ & \\
\hline Total & 27 parameters & & 2 parameters & 10 parameters & 14 parameters \\
\hline
\end{tabular}

HAAs (haloacetic acids) refer to the sum of dichloroacetic acid, dibromoacetic acid, trichloroacetic acid, monochloroacetic acid, and monobromoacetic acid.

규 조사항목 등 총 70 종의 오염물질에 대한 조사가 진행되었다. 35 개 주요 정수장에서 연간 4회 정수를 채수하여 70 종의 오염물질의 함유실태를 분석하였으며, 이 중 12 개 정수장에서는 원수에 대해서 도 조사가 수행되었다[11]. 실태조사에서는 원수와 정수에서 검출되 는 미지의 물질에 대한 스크리닝도 함께 이루어진다. 분석 결과를 물 질별 라이브러리와 비교하여 물질의 종류를 추정하고 해당 물질의 표준시료를 구입하여 물질의 최종 확인이 이루어진다. 또한 검출된 항목에 대해서는 위해성을 평가하여 향후 조치를 마련한다[11].

\section{2-1-5. 「새로운 미량유해물질 발견시 처리규정안」}

환경부 훈령인「새로운 미량유해물질 발견 시 처리규정안」은 수돗물, 하천·호소수에 대한 각종 실태조사에서 발견된 신규 오염물 질이 국민건강에 위해를 줄 우려가 있는 경우에 정부가 취해야 하는 필요한 조치를 규정하고 있다[12]. 여기서 미량유해물질이란 먹는 물 수질기준이나 배출허용기준이 마련되지 않은 물질로 “사람 및 동·식 물에 발암성 등 독성이 있는 것으로 확인된 물질"을 가리킨다. 위 훈 령은 미량유해물질 발견 시 (1) 발견, (2) 대책, (3) 대응, (4) 장기대 책의 4단계로 필요한 조치를 규정하고 있다. 미량유해물질 발견 시 지방자치단체장은 반복적인 시료채취 및 분석을 통해 해당 물질의 위해성을 검증한 후 환경부장관에 보고한다. 환경부장관은 상황실을 설치하여 정수장 대응방안, 응급조치 사항 등 유해물질 관리대책을
수립한다. 그리고 지자체 상수도사업본부, 보건환경연구소 등 유관 기관이 참여하여 시료 분석, 실험·분석방법 전수, 정수장 오염도 측 정, 처리방법 강구 등의 대응이 이루어진다. 장기적으로는 해당 물질 을 다량으로 사용하는 사업장에 대한 조사와 하천 지점별로 오염물 질의 유출 경로를 추적하는 배출원 파악이 이루어진다[12].

2006년 낙동강에서 당시 관리대상이 아니었던 perchlorate가 하천과 수돗물에서 발견되는 사건이 발생하였다. 해당물질은 낙동강 수계에 입지한 공장에서 배출되는 오염물질로, 전국의 하천·호소수 및 먹는 물에 대해 실태조사를 실시하거나 수질기준을 정하여 관리하기에는 어려움이 따른다. 이에 환경부는 대구 강정 취수장 상류의 왜관대교 지점에서 갈수기 기준으로 perchlorate 농도가 $6 \mu \mathrm{g} / \mathrm{L}$ 이하로 유지 되도록 가이드라인을 설정하였으며, perchlorate 관리를 위한 배출 기업, 경상북도, 대구지방환경청 등 3자 간의 '자발적 협약서'를 체결 하였다.

2-1-6. 「항생제 내성관리 종합대책」

수중 잔류 의약물질 관리를 위해 국무조정실, 농림부, 보건복지부, 환경부, 해양수산부, 식품의약품안전청 등 관계기관이 참여하여 「항 생제 내성관리 종합대책(2008 2012)」을 수립·추진하였다[13]. 환경 부는 위 대책에 따라 하천수에 대한 잔류 의약물질 실태조사를 실시 하고 있으며, 하수처리장과 축산폐수처리장의 유입수와 방류수를 조 
사하여 잔류 의약물질의 배출원 및 배출경로를 규명하는 연구를 수 행하였다. 그 외에도 병원, 제약공장 등 배출원에서 의약물질의 배출 을 줄일 수 있는 폐수처리기법과 정수장에서 해당 물질을 처리하기 위한 정수처리공정에 대한 연구가 수행되었다. 그리고 가정에서 나 오는 폐의약품을 회수·수거하는 사업을 2008년부터 진행하고 있다.

\section{2-2. 관련 해외 사례}

\section{2-2-1. 미국 USGS Toxics 프로그램}

미국 지질조사국(U.S. Geological Survey, USGS)은 전국 수문 환 경에 존재하는 독성 물질의 거동을 연구하는 Toxic Substances Hydrology (Toxics) 프로그램을 진행하고 있으며, 위 프로그램의 세부 과제로 미량오염물질에 대한 조사-연구가 이루어지고 있다 [14]. 'Toxics' 프로그램의 세부 주제인 'Emerging Contaminants' 에서는 환경에 유입되는 경우 생태계나 인간 건강에 악영향을 미 치거나 또는 악영향이 우려되는 천연·인공화합물 또는 미생물에 대한 조사·연구를 진행하고 있다. 'Emerging Contaminants' 프로 그램은 단순히 수중 미량오염물질의 조사에만 그치지 않고, 퇴적 물, 폐기물 등 다양한 매질에 대해 미량오염물질을 측정하는 분석 방법을 개발하고 미량오염물질의 배출원과 배출 경로를 파악하는 작업이 함께 진행된다. 또한 환경에서 오염물질이 거동하는 프로 세스를 확인하고 정량화하는 작업과 이들 미량오염물질에 의한 잠 재적인 생태적 영향을 확인하는 연구가 수행되었다. 이러한 조 사-연구 프로그램을 통해 물, 퇴적물, 생물체 조직에 잔류하는 250 종 이상의 화학물질에 대한 분석방법과 미생물 분석방법의 개발이 진행되었으며, 퇴적물, 수돗물 원수, 지하수, 국가하천 등 광범위한 규모의 전국 수계에 대한 미량오염물질 조사가 이루어졌다. 그리 고 폐수처리장, 슬러지, 매립지 침출수, 가축사육시설, 양식장 등 오염물질 배출원에 대한 조사가 수행되었으며, 내분비계 장애물질, 항 균제 내성, 병원성 미생물에 의한 생태학적 영향 등에 대한 연구가 이루어졌다[15].

\section{2-2-2. 스위스「Strategie MicroPoll」프로젝트}

스위스 연방환경청(FOEN)은 2006년부터 2011년까지 하수처리장 에서 발생하는 미량오염물질이 지표수로 유입되는 것을 방지하기 위 한「Strategie MicroPoll」 프로젝트를 진행하였다. 이 프로젝트는 미량오염물질 현황 분석, 평가방법 개발, 처리기술 등을 다루고 있다 [16]. 미량오염물질의 시·공간적인 분포를 적은 비용과 노력으로 파 악할 수 있도록 하기 위해 기존의 자료를 활용하여 개별 오염물질의 분포를 모의하는 모델을 개발하는 연구가 진행되었다[17]. 도시지역 의 지표수 및 하수에 포함된 미량오염물질의 파악을 위해 수생태계 또는 인체에 독성을 나타내는 250 여개의 미량오염물질 목록을 작성 하였으며 각 물질에 대한 분석방법을 연구하였다. 그리고 개별 항목 의 생태 독성 분석결과를 토대로 수질기준을 설정하는 것이 필요한 지 여부를 검토한다[17].

「Strategie MicroPoll」 프로젝트에서 특히 눈길을 끄는 연구는 미 량오염물질의 제거효율을 평가하기 위해 하수처리장에서 수행하고 있는 파일럿 규모의 연구이다. 이 실험은 오존, 활성탄 등 추가적인 하-폐수처리공정의 도입 타당성을 판단하기 위한 것으로 실제 규모 및 조건에서 실험이 진행되었다. Regensdorf의 하수처리장에서 오존 처리 공정의 미량오염물질의 제거 성능에 대한 평가 결과, 오존처리 가 기술적으로 그리고 경제적으로 실현가능한 것으로 결론이 얻어졌
다[18]. 이후 Lausanne의 하수처리장에서 더 큰 규모로 두 번째 파 일럿 규모 연구가 진행 중이며, 소규모로 분말활성탄을 이용한 미 량유해물질의 흡착효율 연구가 함께 진행되었다. 그 외에도 병원, 노인요양원 등에서 발생하는 하수에서 미량오염물질의 분리가 가능 한지, 하수의 오존처리 과정에서 발생하는 부산물이 문제가 되지는 않는지, 단일 미량오염물질과 여러 미량오염물질의 혼합물이 수생 생물에 미치는 악영향은 어떤 것인지 등에 대한 추가적인 연구를 지 원하고 있으며, 일반 시민들과 관련된 기관 및 전문가에게 정보를 제공하고 있다[17].

\section{3. 국내 수중 미량오염물질 검출 현황}

\section{3-1. 하천수 미량오염물질 검출 사례}

낙동강수계관리위원회는 2007 2008년 낙동강 수계를 대상으로 잠정관리 유해물질에 대한 조사를 수행하였다[8]. 낙동강 중권역 대 표지점 33 곳과 공단배수 5지점 등 총 38 개 지점에서 VOCs, PAHs, 프탈레이트, 농약 등 총 60 개 항목에 대해 연 3회 조사를 진행하였다. VOCs 22 개 항목은 1 3차 조사까지 모든 지점에서 검출되지 않았다. 한편, 환경부의 다른 조사에서는 vinyl chloride, trichloroethylene, toluene, ethylbenzene이 금호강과 수영강에서 각각 ND 3.79 $\mu \mathrm{g} / \mathrm{L}$, $\mathrm{ND} 1.29 \mu \mathrm{g} / \mathrm{L}$ 로 미량 검출된바 있다[19]. 농약류인 Malathion, Diazinon, Atrazine은 모든 지점에서 검출되지 않았고 Simazine은 대 암1 지점에서만 $0.088 \mu \mathrm{g} / \mathrm{L}$ 로 1회 검출되었다. Simazine의 검출수준은 미국과 $\mathrm{WHO}$ 의 수질기준의 $1 / 25 \sim 1 / 50$ 수준에 불과하였다. Heptachlor 의 대사산물인 Heptachlor epoxide는 모든 조사에서 검출되지 않았 다. Alachlor와 Methoxychlor는 각각 1회 $(0.065 \mu \mathrm{g} / \mathrm{L})$ 및 2회(0.032, $0.079 \mu \mathrm{g} / \mathrm{L}$ ) 검출되었으나, 그 농도는 WHO와 미국 먹는 물 가이드 라인의 1/250 1/300 수준으로 매우 낮았다. 카바메이트게 농약인 Carbaryl과 Methomyl은 모든 지점에서 검출되지 않았다. 그러나 벼 와 옥수수 재배에서 광범위하게 사용되는 카바메이트계 살충제인 Carbofuran은 위천6 지점에서 $12.67 \mu \mathrm{g} / \mathrm{L}$, 삼랑진에서 $12.67 \mu \mathrm{g} / \mathrm{L}$ 의 농도로 검출되는 등 2차 조사(2008년 7월)에서 다수 지점이 $\mathrm{WHO}$ 의

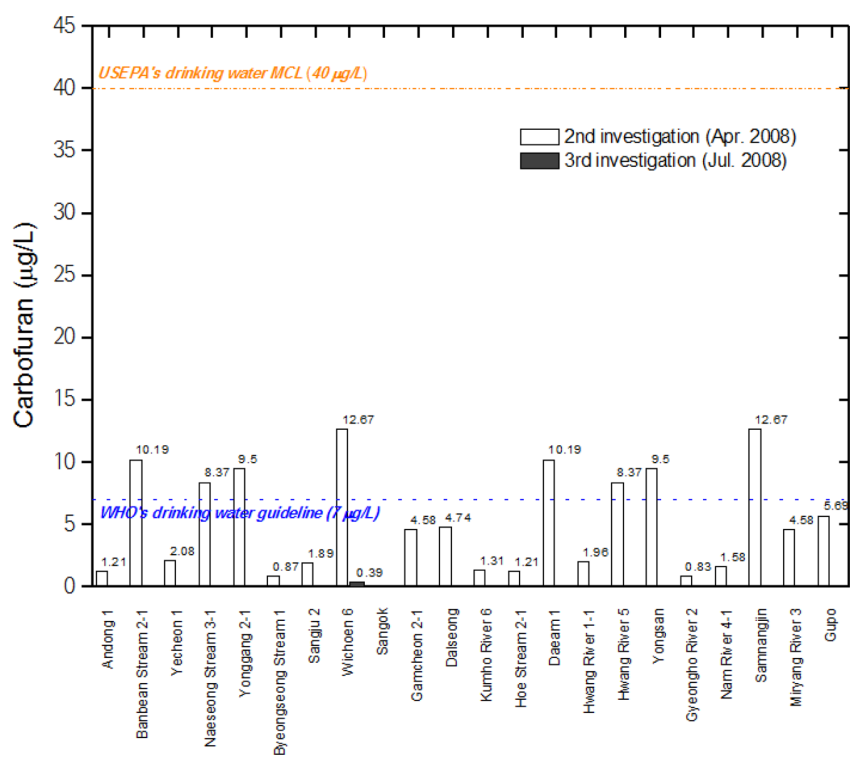

Fig. 1. The carbofuran concentration at the selected sites of Nakdong River basin (Data from [8]). 
먹는 물 가이드라인인 $7 \mu \mathrm{g} / \mathrm{L}$ 을 넘는 것으로 조사되었으나, 미국의 먹는 물 최대오염수준(maximum contamination level, MCL)인 $40 \mu \mathrm{g} / \mathrm{L}$ 를 초과하지는 않았다(Fig. 1). 그 외 Endrin, Chlordan, Heptachlor는 1 3차 조사 동안 모든 지점에서 검출되지 않았다. Carbofuran을 제 외하고는 농약류가 낙동강 수계 하천에서 검출되지 않은 이유는 맹 독성 농약류가 농약관리법에 의해 69년부터 사용이 금지되었거나, 국내에서 일찍부터 관리가 되거나 유통실적이 없기 때문인 것으로 판단된다[20]. 플라스틱 가소제, 화장품 등에 사용되는 프탈레이트류에 대한 조사결과 diethyl phthalate는 전 지점에 검출되지 않았다. 그 외 di-n-butyl phthalate가 N.D 17.27 $\mu \mathrm{g} / \mathrm{L}$ 로 측정되었고, butyl benzyl phthalte가 2회 $(1.08 \mu \mathrm{g} / \mathrm{L}, 3.75 \mu \mathrm{g} / \mathrm{L})$, bis(2-ethylhexyl) adipate가 1회 $(2.67 \mu \mathrm{g} / \mathrm{L})$ 검출되었다. 이들 물질의 검출수준은 미국의 수질 기준 에 비해 1/100 1/150으로 매우 낮은 수준이었다. Chlorobenzene 류와 16 개 PAHs는 모든 조사지점에서 검출되지 않았다. 다른 연구에서도 anthracene과 pyrene는 공단천과 하폐수처리장에서 검출되지 않았 다[21]. 그러나 발암물질인 PAHs에 대해서는 HRGC/HRMS(high resolution $\mathrm{GC} / \mathrm{MS}$ ) 등을 사용해 검출한계를 향상해야 할 필요가 있는 것으로 지적되었다[8].

한편, 환경부는 2007년 하천, 하수처리장, 축산폐수처리장 등 총 40 개 지점을 대상으로 27 종의 의약물질의 잔류농도를 조사하였다 [22]. 조사대상 27종의 의약물질 중 하천수, 하수처리장 방류수와 축
산폐수처리장 방류수에서 각각 $15,13,16$ 종의 의약물질이 검출되었 다. 하천수에서는 인체·동물용 항생·항균제인 chlortetracycline의 농도

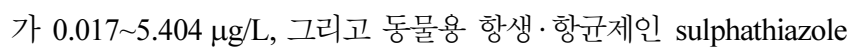
의 농도가 $0.010 ~ 1.882 \mu \mathrm{g} / \mathrm{L}$ 로 비교적 높게 검출되었다. 아스피린으로 불리는 진통·해열·소염제인 acetylsalicylic acid의 평균 검출농도는 $0.064 \mu \mathrm{g} / \mathrm{L}$ 로 높지 않았으나 32지점에서 검출되어 검출빈도가 $80 \%$ 로 가장 높았다. 하천수에서 검출된 의약물질의 농도는 해외에서 보 고된 수준과 비슷하거나 약간 높은 수준이었다[22]. 하수처리장의 유 입수에서는 Lincomycin, erythromycin- $\mathrm{H}_{2} \mathrm{O}$, acetylsalicylic acid이 모든 조사지점에서 검출되었다. 하수처리장 유입수 중의 의약물질 평균 농도는 acetaminophen $(26.910 \mu \mathrm{g} / \mathrm{L})$ 과 acetylsalicylic acid $(5.113 \mu \mathrm{g} / \mathrm{L})$ 을 제외하고는 $1 \mu \mathrm{g} / \mathrm{L}$ 내외거나 이보다 낮았다. 하수처 리장 유입수에서 비교적 높게 측정된 이들 두 물질은 처리 후 방류 수에서 평균농도가 acetaminophen과 acetylsalicylic acid이 각각 N.D 및 $0.116 \mu \mathrm{g} / \mathrm{L}$ 로 크게 낮아졌다. 축산폐수처리장에서는 Chlortetracycline 이 모든 유입수 시료에서 검출되었으며 평균 검출농도가 $1,119.48 \mu \mathrm{g} /$ $\mathrm{L}$ 에 달하는 등 의약물질의 농도가 높게 조사되었다. 처리 후에도 하 수처리장보다 축산폐수처리장의 방류수 중의 의약물질이 높은 농도 로 검출되었다. 그러나 이들 처리장 인근에서 측정한 하천수 중의 의 약물질 농도는 큰 차이가 없었다[22].

Table 2. The Pharmaceutical concentrations at the influent, effluents and nearby river water of the municipal wastewater treatment plant (data from [22])

\begin{tabular}{|c|c|c|c|c|c|c|c|}
\hline \multirow[b]{2}{*}{ Substances } & \multicolumn{6}{|c|}{ Mean detected concentration (min.-max.) $(\mu \mathrm{g} / \mathrm{L})$} & \multirow[b]{2}{*}{$\begin{array}{c}\text { Detection } \\
\operatorname{limit}(\mu \mathrm{g} / \mathrm{L})\end{array}$} \\
\hline & Influent & $\begin{array}{l}\text { \# of detected } \\
(n=10)\end{array}$ & Effluent & $\begin{array}{l}\text { \# of detected } \\
\quad(n=10)\end{array}$ & nearby river water & $\begin{array}{l}\text { \# of detected } \\
(n=24)\end{array}$ & \\
\hline Acetaminophen & $26.910(15.40-50.00)$ & 9 & N.D. & - & 0.137 & 1 & 0.0001 \\
\hline Sulfathiazole & 0.031 & 1 & N.D. & - & $0.494(0.01-1.88)$ & 4 & 0.0002 \\
\hline Sulfamethazine & N.D. & - & N.D. & - & 0.296 & 1 & 0.00002 \\
\hline Carbadox & N.D. & - & N.D. & - & N.D. & - & 0.0001 \\
\hline Sulfamethoxazole & $1.025(0.32-2.02)$ & 9 & $0.496(0.15-0.82)$ & 8 & $0.086(0.04-0.17)$ & 5 & 0.002 \\
\hline Lincomycin & $0.263(0.09-0.56)$ & 10 & $0.214(0.01-0.51)$ & 9 & $0.061(0.002-0.25)$ & 8 & 0.00009 \\
\hline Trimethoprim & $0.043(0.03-0.06)$ & 6 & $0.040(0.008-0.07)$ & 6 & $0.010(0.008-0.01)$ & 2 & 0.0006 \\
\hline Chlortetracycline & $0.527(0.04-1.78)$ & 5 & $0.184(0.03-0.41)$ & 5 & $0.823(0.02-5.40)$ & 9 & 0.0002 \\
\hline Oxytetracycline & N.D. & - & N.D. & - & N.D. & - & 0.0004 \\
\hline Enrofloxacin & N.D. & - & N.D. & - & $0.048(0.03-0.08)$ & 3 & 0.0002 \\
\hline Ciprofloxacin & 0.013 & 1 & $0.085(0.001-0.24)$ & 3 & 0.001 & 1 & 0.0001 \\
\hline Erythromycin- $\mathrm{H}_{2} \mathrm{O}$ & $0.178(0.07-0.34)$ & 10 & $0.090(0.04-0.21)$ & 9 & $0.028(0.025-0.033)$ & 7 & 0.0004 \\
\hline Tyrosine & N.D. & - & N.D. & - & N.D. & - & 0.0005 \\
\hline Diclofenac Sodium & 0.019 & 1 & $0.050(0.030-0.079)$ & 5 & N.D. & - & 0.002 \\
\hline Naproxen & $1.096(0.33-3.31)$ & 7 & $0.114(0.01-0.39)$ & 5 & $0.030(0.01-0.07)$ & 6 & 0.0002 \\
\hline Ibuprofen & $0.767(0.18-1.25)$ & 3 & 0.075 & 1 & N.D. & - & 0.002 \\
\hline Talniflumate & N.D. & - & N.D. & - & N.D. & - & 0.005 \\
\hline Mefenamic acid & $0.212(0.002-0.99)$ & 8 & $0.264(0.05-0.64)$ & 9 & $0.026(0.01-0.07)$ & 8 & 0.0009 \\
\hline Cefadroxil & N.D. & - & 0.093 & 1 & N.D. & - & 0.005 \\
\hline Amoxicillin & N.D. & - & N.D. & - & N.D. & - & 0.006 \\
\hline Ampicillin & N.D. & - & N.D. & - & N.D. & - & 0.001 \\
\hline $\begin{array}{ll}\text { Penicillin G } & \text { Penicillin G } \\
\text { Procaine } & \text { Procaine }\end{array}$ & N.D. & - & N.D. & - & N.D. & - & 0.007 \\
\hline Neomycin & 1.380 & 1 & 7.830 & 1 & 0.94 & 1 & 0.00008 \\
\hline Acetylsalicylic acid & $5.113(0.09-12.69)$ & 10 & $0.116(0.035-0.22)$ & 7 & $0.079(0.029-0.269)$ & 21 & 0.0005 \\
\hline Cefatrizine & N.D. & - & N.D. & - & N.D. & - & 0.08 \\
\hline Cefaclor & N.D. & - & N.D. & - & N.D. & - & 0.01 \\
\hline Cefradine & $0.102(0.08-0.12)$ & 3 & N.D. & - & N.D. & - & 0.005 \\
\hline
\end{tabular}




\section{3-2. 수돗물 원수/정수 미량오염물질 검출 사례}

국립환경과학원은 2012년 수질감시항목(18개), 수질모니터링 후 보항목(43개), 2012년도 신규조사항목(12개) 등 현행 먹는 물 수질 기준에 포함되어 있지 않은 총 73개 항목에 대한 조사를 정수장 정 수 및 원수를 대상으로 실시하였다[23].

40 개 정수장에서 채취한 총 160 개 수돗물(정수) 시료의 미량오염 물질 검출결과는 다음과 같다(Table 2). 먹는 물 감시항목(18개) 중 에서는 소독부산물인 Bromochloroacetonitrile $(0.17 \sim 1.54 \mu \mathrm{g} / \mathrm{L})$, Antimony $(0.03 \sim 4.80 \mu \mathrm{g} / \mathrm{L})$, Chlorate $(0.22 \sim 1335.41 \mu \mathrm{g} / \mathrm{L})$ 등이 절반 이상의 시 료에서 검출되었다. 수질모니터링 후보항목(43개) 중, Chloropicrin (0.16 5.07 $\mu \mathrm{g} / \mathrm{L})$, 1,1-Dichloropropanone $(0.17 \sim 5.12 \mu \mathrm{g} / \mathrm{L}), 1,1,1$ Trichloropropanone (0.09 4.30 $\mu \mathrm{g} / \mathrm{L})$, Dichloroacetaldehyde (0.22 13.54 $\mu \mathrm{g}$ ) L) 등 소독부산물과 할로아세틱산(haloacetic acids, HAAs)의 일종인 Bromochloroacetic acid $(0.34 \sim 9.59 \mu \mathrm{g} / \mathrm{L})$ 가 절반 이상의 시료에서 검 출되었다. 2012년 신규 조사항목(12개) 중에서는 과불화화합물 (Perfluorinated compounds, PFC) 종류인 Perfluorooctanesulfonate (PFOS, 0.40 37.40 ng/L), Perfluoropentanoic acid (PFPA, 1.10 8.51 ng/L), Perfluorohexanoic acid (PFHxA, 0.50 9.60 ng/L), Perfluorooctanoic acid (PFOA, 1.00 20.02 ng/L)가 절반 이상의 시료에서 검출되었다[23].

Table 3 은 12 개 정수장에서 취수하는 상수원수 48 개 시료의 미량 오염물질 검출결과를 보여준다. 수질감시항목 중에서는 금속물질인 Antimony $(0.03 \sim 0.95 \mu \mathrm{g} / \mathrm{L})$ 가 대부분의 시료에서 검출되었으며 절반에 가까운 시료에서 냄새유발물질인 Geosmin (3.01 19.82 ng/L)이 검출되 었다. 수질모니터링 후보항목 중 1,1-Dichloropropanone (0.16 0.26 $\mu \mathrm{g} / \mathrm{L}), 1,1,1-$ Trichloropropanone $(0.15 \mu \mathrm{g} / \mathrm{L})$, Dichloroacetaldehyde $(0.54 \sim 3.60 \mu \mathrm{g} / \mathrm{L})$, Bromochloroacetic acid (0.97 2.14 $\mu \mathrm{g} / \mathrm{L})$, 2,3-Dimethyl2-butanol $(0.05 \mu \mathrm{g} / \mathrm{L})$ 등이 검출되었으나 총 48 개 시료 중 $1 \sim 4$ 개 이하의 시료에서만 검출되었다. 신규 조사항목 중에서는 PFPA (1.25 8.23 $\mathrm{ng} / \mathrm{L}), \mathrm{PFHxA}(0.51 \sim 6.30 \mathrm{ng} / \mathrm{L})$, PFOA (1.08 17.10 ng/L) 등의 PFCs와 우라늄 $(0.02 \sim 0.33 \mu \mathrm{g} / \mathrm{L})$ 이 절반 이상의 시료에서 검출되었다[23].

Bromoform, Bromochloroacetonitrile, Formaldehyde, Chlorate, Bromate, Dichloroacetaldehyde, Bromochloroacetic acid 등은 원수보다 정수된 수돗물에서 더 높았는데, 이는 이들 물질이 산화과정에서 생성되는 부산물이기 때문으로 판단된다. 이러한 결과는 먹는 물에서는 소독 부산물 종류의 미량오염물질 관리가 중요함을 의미한다. 냄새 유발 물질인 Geosmin은 원수의 농도보다 정수의 농도가 낮아 정수처리공 정이 Geosmin 저감에 일정한 역할을 하는 것을 보여준다. 농약류인 2,4-D, 냄새 유발물질인 2-MIB, Perchlorate 등 원수에서 검출되지 않 은 물질이 정수에서 검출되었으나, 검출 빈도는 1 2회로 매우 낮아 일부 지역에서의 일시적인 농도 상승으로 추정된다. $\mathrm{PFCs}$ 또한 $\mathrm{ng} / \mathrm{L}$ 수준의 낮은 농도이긴 하나 다수의 원수 및 정수 시료에서 검출되었 다. 국내 PFCs의 먹는 물 농도, 혈중 농도, 배출량 추정값은 일본이 나 미국 등 다른 선진국에 비해 낮은 것으로 평가되나, 정확한 평가 를 위해서는 더 많은 연구와 연구결과 사이의 상호보완 및 평가가 필 요한 것으로 판단된다[24,25].

위의 조사에서 발암가능성이 있는 bromate의 경우에 검출농도의 상위 5 분위(95 percentile)에 해당하는 초과발암위해도는 $1.08 \times 10^{-5}$ 로 계산되었다. 이는 $\mathrm{WHO}$ 의 허용 권고치 $\left(1.0 \times 10^{-5}\right)$ 보다 높은 값이

Table 3. The concentrations of drinking water surveillance substances in the produced tap water (40 sites) (Data from [23])

\begin{tabular}{|c|c|c|c|c|}
\hline Categories & Groups & Substances & $\#$ of detected samples $(n=160)$ & Detected level \\
\hline \multirow{10}{*}{ Surveillance substances } & $\mathrm{VOCs}^{1}$ & Bromoform & 3 & $0.73-1.46 \mu \mathrm{g} / \mathrm{L}$ \\
\hline & $\mathrm{DBPs}^{2}$ & Bromochloroacetonitrile & 112 & $0.17-1.54 \mu \mathrm{g} / \mathrm{L}$ \\
\hline & $\mathrm{ACs}^{3}$ & $2,4-\mathrm{D}$ & 1 & $35.11 \mathrm{ng} / \mathrm{L}$ \\
\hline & \multirow{2}{*}{ Odorant } & Geosmin & 31 & $3.06-9.18 \mathrm{ng} / \mathrm{L}$ \\
\hline & & 2-MIB & 2 & 9.94-10.46 ng/L \\
\hline & Miscellaneous & formaldehyde & 78 & 6.09-34.64 ng/L \\
\hline & Metals & Antimony & 154 & $0.03-4.80 \mu \mathrm{g} / \mathrm{L}$ \\
\hline & \multirow{3}{*}{ Inorganics } & Chlorate & 112 & $0.22-1335.41 \mu \mathrm{g} / \mathrm{L}$ \\
\hline & & Bromate & 18 & $0.53-4.87 \mu \mathrm{g} / \mathrm{L}$ \\
\hline & & Perchlorate & 2 & $2.47-11.81 \mu \mathrm{g} / \mathrm{L}$ \\
\hline \multirow{5}{*}{$\begin{array}{l}\text { Surveillance candidate } \\
\text { substances }\end{array}$} & \multirow{3}{*}{$\mathrm{DBPs}^{2}$} & Chloropicrin & 86 & $0.16-5.07 \mu \mathrm{g} / \mathrm{L}$ \\
\hline & & 1,1-Dichloropropanone & 143 & $0.17-5.12 \mu \mathrm{g} / \mathrm{L}$ \\
\hline & & 1,1,1-Trichloropropanone & 125 & $0.09-4.30 \mu \mathrm{g} / \mathrm{L}$ \\
\hline & $\mathrm{HAAs}^{4}$ & Bromochloroacetic acid & 157 & $0.34-9.59 \mu \mathrm{g} / \mathrm{L}$ \\
\hline & Miscellaneous & 2,3-Dimethyl-2-butanol & 1 & $0.05 \mu \mathrm{g} / \mathrm{L}$ \\
\hline \multirow{8}{*}{ New target substances } & \multirow{7}{*}{$\mathrm{PFCs}^{5}$} & $\mathrm{PFHxS}^{6}$ & 5 & $1.50-5.90 \mathrm{ng} / \mathrm{L}$ \\
\hline & & $\mathrm{PFOS}^{7}$ & 94 & $0.40-37.40 \mathrm{ng} / \mathrm{L}$ \\
\hline & & $\mathrm{PFPA}^{8}$ & 130 & $1.10-8.51 \mathrm{ng} / \mathrm{L}$ \\
\hline & & $\mathrm{PFHxA}^{9}$ & 117 & $0.50-9.60 \mathrm{ng} / \mathrm{L}$ \\
\hline & & PFHpA $^{10}$ & 74 & $0.33-13.40 \mathrm{ng} / \mathrm{L}$ \\
\hline & & $\mathrm{PFOA}^{11}$ & 94 & $1.00-20.02 \mathrm{ng} / \mathrm{L}$ \\
\hline & & PFNA $^{12}$ & 64 & $0.40-6.50 \mathrm{ng} / \mathrm{L}$ \\
\hline & Metals & Uranium & 27 & $0.01-0.41 \mu \mathrm{g} / \mathrm{L}$ \\
\hline \multicolumn{2}{|c|}{${ }^{1}$ Volatile organic compounds } & Perfluorinated Compounds & \multicolumn{2}{|c|}{${ }^{9}$ Perfluorohexanoic acid } \\
\hline \multicolumn{2}{|c|}{${ }^{2}$ Disinfection by-products } & Perfluorohexanesulfonic acid & \multicolumn{2}{|c|}{${ }^{10}$ Perfluoroheptanoic acid } \\
\hline \multicolumn{2}{|l|}{${ }^{3}$ Agricultural chemicals } & 7Perfluorooctanesulfonate & \multicolumn{2}{|c|}{${ }^{11}$ Perfluorooctanoic acid } \\
\hline
\end{tabular}

Korean Chem. Eng. Res., Vol. 51, No. 6, December, 2013 
Table 4. The concentrations of drinking water surveillance substances in the raw river or lake water (12 sites) (Data from [23])

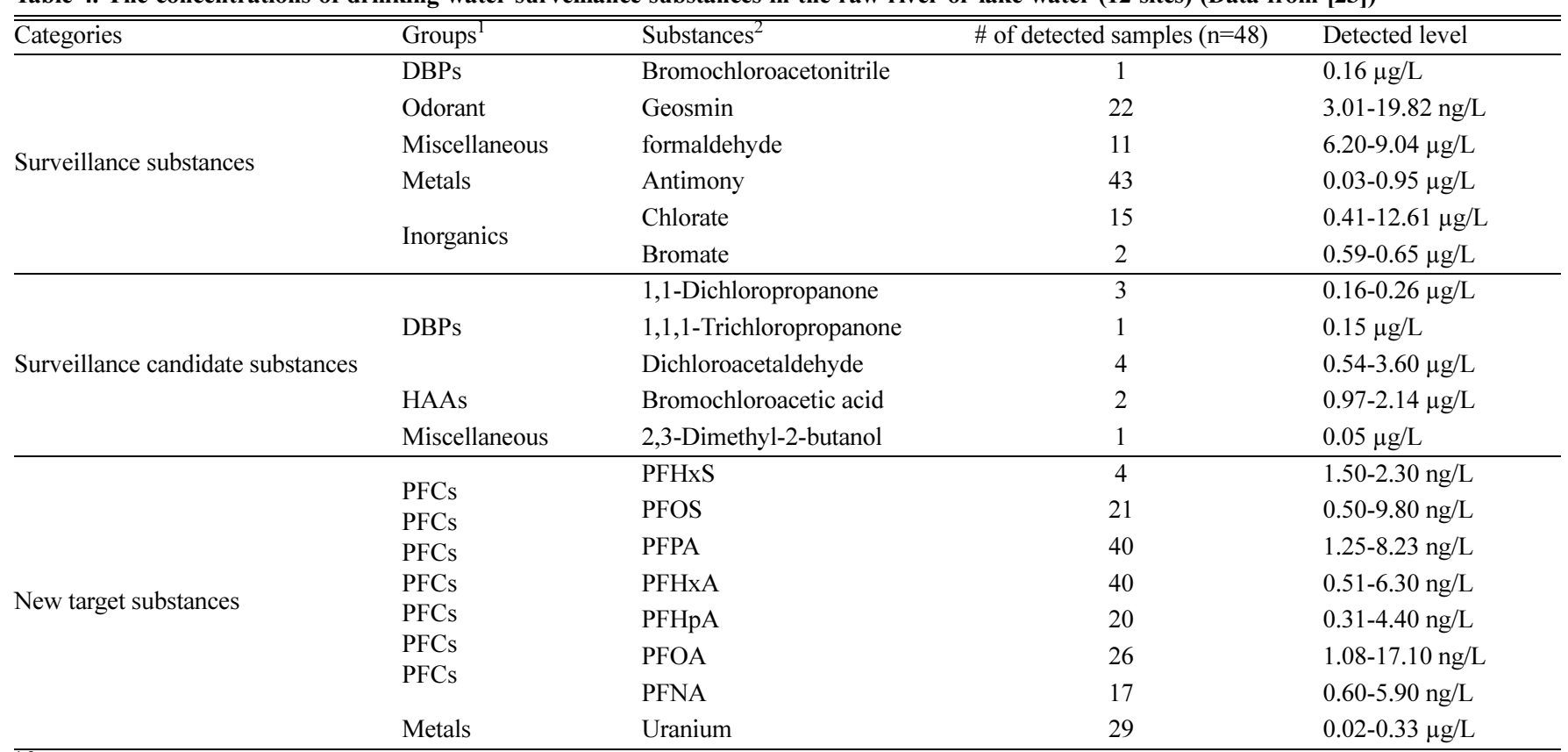

${ }_{1,2}$ Refer to the footnote of Table 2 for the full name of each abbreviation.

다. 그러나 최근 3년 간(2010 2012년) 조사에서 총 검출빈도가 $5.9 \%$ 로 낮아 먹는 물 수질기준 항목으로 추가하는 것보다는 감시항목으 로 계속 지정하여 검출빈도 및 농도 추이를 관찰하는 것이 합리적일 것으로 판단되었다[23]. 한편, 전체 시료 중 $10 \%$ 이상의 시료에서 검출 된 18 종의 물질 중 독성 참고값이 존재하는 4 개 물질(formaldehyde, antimony, bromate, 우라늄)에 대해 노출량과 참고값을 비교하였다. 그 결과, 각각의 비발암 위험지수는 1 보다 낮았으며 각 항목의 위험 지수의 합인 총 위험지수 또한 0.0536 으로 수돗물 내 이들 물질의 농 도는 안전한 수준으로 평가되었다[23].

\section{4. 기후변화 등 잠재적 영향 검토}

\section{4-1. 기후변화}

기후변화로 지구의 표면 온도가 상승하면서 수온 상승, 강우량 증 가, 해수면 상승 등이 발생하며 수질 오염물질의 발생 및 거동에도 영향이 있을 것으로 예측된다. UNEP의 장기 모니터링에서 아프리 카, 아메리카, 유럽, 아시아 지역의 호수와 저수지의 표층 수온이 지 난 수십 년간 뚜렷하게 상승하는 것으로 나타났는데, 이러한 변화는 수질과 수생태계에 긍정적 또는 부정적인 영향을 가져올 수 있다 [26]. 기후변화가 진행됨에 따라 수질에 다음과 같은 부정적인 영향 을 예상할 수 있다. 수온 증가로 온도에 민감한 종이 멸종할 우려가 있으며 용존 산소량이 감소하여 수체 내에 무산소(anoxia) 환경이 발 생할 수 있다. 수온 상승으로 유기물의 분해 속도가 증가할 경우 용 존산소가 급격히 줄어들 수 있다. 호소에서는 해빙 시점이 빨라지며 호소의 성층화(stratification) 패턴이 바뀔 수 있다. 또한 대기의 화학 적 조성이 바뀌면서 UV 복사가 증가하여 수생 생물의 성장과 번식 에 영항을 줄 수 있다. 그 외에도 수문학적 순환의 변화로 홍수와 가 뭄의 패턴, 강도, 지속시간 등 물순환 전반이 크게 영향을 받을 것으 로 전망되며, 이러한 변화는 토사 등 비점오염물질의 유입 증가를 가 져올 수 있다[26]. 특히, 하수처리장에서 처리되지 못하고 수계로 방
류되는 합류식 관거 월류수(combined sewer overflows, CSOs)는 도 시지역의 주요 비점오염원이자 미량오염물질의 오염원이기도 하다. 일부 호르몬 물질의 경우 $\mathrm{CSOs}$ 에서의 농도가 하수처리장 방류수의 농도에 비해 10 배 이상 높으며, 하수처리장 방류수 및 CSOs에서 배 출되는 미량오염물질의 부하량의 $40 \sim 90 \%$ 가 CSOs에 의한 것이라는 사례 연구가 최근 발표되었다[27]. 국내에서도 하수관거의 차집 용 량을 초과하는 강우가 내려 도시가 침수되는 사고가 발생한 적이 있 는데, 강우 강도와 지속시간의 증가는 도시의 안전뿐 아니라 도심 하 천 및 하류 하천의 미량오염물질의 농도에도 영향을 줄 것으로 예상 된다.

기후변화에 따라 수중 미량오염물질이 어떠한 영향을 받을지 아 직 명확하지는 않으나 다음과 같은 우려가 존재한다. 기후변화에 따 른 수문변화로 하천의 유황이 변화하면서 하수처리장 방류수 등 점 오염원이 지표수에 미치는 영향이 상대적으로 커질 수 있다. 예를 들 어, 기후변화로 하천의 유량이 줄어든다면 다수의 미량오염물질이 포함된 하수처리장 방류수가 제대로 희석되지 않아 하천수의 미량오 염물질 농도가 증가할 수 있다[28]. 여러 미량오염물질이 존재하는 경우 개별물질의 농도는 낮더라도 혼합하여 존재하는 경우에는 부가 적인 악영향이 발생할 수 있다. 기후변화로 수온 상승 및 UV 복사 증가가 발생하는 경우, 이러한 외부 환경변화가 새로운 스트레스로 작용하여 미량오염물질에 노출된 생물체에 부가적인 압력을 가할 수 있다[29]. 예를 들어, 기후변화가 급속도로 진행 중인 북극에 서식하 는 해양 포유류와 해양성 조류(鳥類)는 기후변화에 따른 먹이 감소 등 환경 변화에 빠르게 적응해야 한다. 그런데 북극에서 검출되는 잔 류성 유기오염물질(persistent organic pollutants, POPs)의 일종인 내 분비계 장애물질(EDCs)은 허물-깃털갈이를 담당하는 갑상선 호르 몬의 작용에 영항을 주거나 성호르몬의 기능을 방해하여 이들 동물 이 기후변화에 적응하는 것을 어렵게 만들 수 있다[30]. 물론 이는 최악의 경우에 해당하며, 국내 생태 환경은 북극과 큰 차이가 있다. 그러나 기후변화가 미량오염물질에 의해 발생하는 생태계 스트레스 
를 증폭시킬 수 있다는 점은 주목해야 할 것이다.

\section{4-2. 물재이용 확대}

미량오염물질은 기후변화보다는 최근 기후변화 적응정책으로 장 려하고 있는 물재이용 과정에서 문제가 될 소지가 더 클 것으로 판 단된다. 호주처럼 기후변화로 물 부족이 심화될 것으로 예측되는 지 역에서는 하·폐수 및 빗물의 재이용을 국가 전역에서 장려하고 있 다. 한국의 경우에 대다수의 취수원을 지표수에 의존하고 있고 하천 의 상류에 오염원이 존재하기 때문에, 시·공간적으로 거리는 떨어져 있으나 상류의 하·폐수가 포함된 하천수를 하류에서 취수 및 정수 하여 먹는 물을 생산한다고 할 수 있다. 이는 하수처리장 방류수가 주요하천의 유량의 대부분을 차지하는 갈수기에 더 뚜렷이 드러난다. 지금은 상류의 하수처리장 방류지점과 하류의 정수장 취수지점이 수 리학적 측면에서 공간적으로 그리고 시간적으로 충분히 떨어져 있는 상황이다. 만약 지역적인 물재이용의 확대로 하수처리수의 방류지점 과 정수장 취수지점 사이의 수리학적인 거리가 줄어든다면, 미량오 염물질이 방류되어 희석되는 과정이 단축되어 잔류 미량오염물질의 농도가 증가하고 새로운 오염물질이 연속적으로 출현할 위험이 커지 게 된다[1]. 물재이용 과정에서 미량오염물질이 농축될 우려가 있으 며, 재이용수를 직 - 간접적인 먹는 물로 이용하는 경우에 미량오염물 질의 농도가 인체 위해성을 나타내는 수준이 아니더라도 시민들의 불안감 및 재이용수에 대한 거부감을 야기할 수 있다.

직 -간접적인 먹는 물 용도로 물을 재이용하지 않는 경우에도 미 량오염물질에 대한 고려가 필요하다. 최근 하천의 수질개선 및 생태 복원을 위해 하-폐수처리장의 방류수를 하천유지용수로 사용하는 사례가 증가하고 있다. 예를 들어, 서울시에서는 59개 하천이 2030 년까지 복원되면서 하천 유지용수가 75 만 $\mathrm{m}^{3} / \mathrm{day}$ 까지 증가할 것으 로 추정되었는데[31], 별도로 수원을 확보하는 것이 어려운 상황에 서 대부분 하수처리장 방류수가 하천유지용수로 공급될 것으로 판단 된다. 도시처럼 인구가 밀집된 환경에서는 하수처리장에 유입되는 미량오염물질의 농도가 높을 수 있으며, 내분비계 장애물질 등 미량 오염물질이 하천으로 유입되어 수생태계에 악영향을 미칠 수 있다.

\section{5. 미량오염물질 관리방향 제언}

지금까지 국내·외 미량오염물질의 관리현황과 국내 지표수 및 먹는 물에서의 미량오염물질 검출현황을 살펴보았다. 그리고 기후변화와 물재이용 등 향후 미량오염물질의 관리에 영향을 줄 수 있는 요소에 대해 정성적인 분석을 시도하였다. 이러한 연구내용을 토대로 다음과 같이 미량오염물질의 관리방향을 제언하고자 한다.

단기적으로는 수도사업자가 수돗물 원수 및 정수에 대한 미량오 염물질 조사대상 항목 및 빈도를 높이도록 하는 것을 고려해볼 수 있 다. 연1회 측정하는 감시항목의 경우 풍수기인 7 9월 사이에 검사를 실시하도록 되어있어서, 갈수기에 수량부족으로 농도가 상승하는 미 량오염물질을 발견하지 못할 우려가 있다. 따라서 국립환경과학원의 수돗물 조사연구와 같이 $2,4,7,9$ 월 등 하천 유량 및 오염물질 농도 의 계절적인 패턴을 확인할 수 있도록 조사 빈도를 높이는 것이 필 요하다. 또한 미량오염물질이 수돗물에서 검출되어 문제가 발생한 지역에서는 지역 수질기준으로 해당 오염물질을 설정하는 등 관리를 강화하는 것이 필요하다. 낙동강 1,4-dioxane 사건 발생 후, 구미지 역 화학섬유업체들은 2004년에 경상북도와 1,4-dioxane 배출량에 대
한 자발적 협약을 체결하였다. 그러나 2009년 1월에 낙동강 본류와 정수장에서 생산된 수돗물에서의 1,4-dioxane 농도가 환경부 가이드 라인인 $50 \mu \mathrm{g} / \mathrm{L}$ 을 초과하는 사태가 발생한 것에서 보듯 자발적인 가 이드라인은 오염물질 관리에 한계가 있다. 따라서 미량오염물질이 가이드라인을 반복적으로 초과할 경우 지역 배출허용기준을 설정하 는 것을 사전에 예고하는 등 강화된 미량오염물질 배출원 관리가 필 요한 것으로 판단된다.

장기적으로는 인간과 환경에 악영향을 미칠 것이라는 증거(연구 결과)가 다수 제시된 미량오염물질에 대해서는 사전예방의 원칙 (precautionary principle)에 따라 지속적인 모니터링, 저감대책 수립 등 적절한 관리대책을 수립하는 것이 필요하다[32]. 특히, 먹는 물에 대해서는 엄격한 미량오염물질 관리정책을 추진할 수 있다. 물론 수 돗물의 미량오염물질 잔류농도는 인체에 악영향을 줄 것으로 판단되 는 수준보다 크게 낮은 것으로 조사되었지만, 수돗물을 비롯한 먹는 물에서는 잔류물질의 독성이 분명히 밝혀졌는지 여부보다는 소비자의 신뢰가 더 중요한 문제이다. 스위스 FOEN의「Strategie MicroPoll」 프로젝트에 보듯 정수과정에서 미량오염물질을 제거하는 것이 기술 적으로 그리고 경제적으로 가능하고 [18], 수도사업자 및 물산업체는 소비자의 신뢰를 매우 중요하게 생각한다는 점을 고려할 때[33], 수 도사업자의 미량오염물질 관리의무를 강화하는 것이 앞으로 필요할 것으로 판단된다.

기존의 수질 관리정책을 충실히 이행하는 것 또한 중요하다. 국내의 상수원 보호구역, 수변구역과 같은 기존의 입지규제 정책은 하천 인 근에서 유해물질이 취급되는 것을 미연에 방지하기 때문에 미량오염 물질로부터 상수원을 보호하는 데에도 효과적이다. 따라서 특정수질 유해물질 등을 취급하는 사업장 등이 상수원 상류에 들어서는 경우 에는 입지의 적정성, 사고 발생 시 비상대응대책 등에 대한 엄격한 기준을 설정하여 환경영향평가가 이루어져야 한다[34]. 산업단지와 같은 점오염원 관리정책으로는 생산 단계에서부터 원료, 에너지, 물의 이용 효율을 높이고 폐수 방류를 최소화하는 청정 생산(clean production) 이 장려되어야 한다[2,35].

그리고 가능하다면 하천수를 직접 취수하는 방식에서 강변여과와 같은 간접적인 방법으로 전환하거나 상류의 댐으로 취수원을 이전하는 것이 가장 바람직할 것이다. 낙동강에서 문제가 되었던 1,4-dioxane에 대한 배출량 감시 등 관리를 강화하더라도, 산업체에서는 1,4dioxane를 물성이 유사한 1,3-dioxolane로 대체하여 사용할 수 있다 [36]. 1,3-dioxolane은 모니터링 대상도 아니며 배출허용치가 정해져 있지도 않기 때문에 관리의 공백이 발생할 수 밖에 없다. 취수원 이 전이 불가능하여 하천수를 직접 취수해야 한다면 응집/침전 공정이 나 염소이산화염소를 이용한 소독공정 등 일반적인 정수처리공정을 활성탄, 고도산화공정, 막분리(나노여과, 역삼투) 공정 등 미량오염 물질 제거효율이 높은 공정으로 고도화하는 것이 필요하다 $[37,38]$. 활성슬러지 공정 등 일반적인 하-폐수처리공정은 유입수의 농도가 낮은 미량오염물질의 처리효율이 높지 않기 때문에[39], 필요한 경 우 오존처리, 활성탄 흡착, 막분리 등의 처리기술을 도입하는 것을 검토할 필요가 있다[40].

\section{감 사}

본 연구는 국무총리실 산하 경제·인문사회연구회의 녹색성장종합 연구 지원으로 수행되었으며(안종호 외, 「기후변화 대응을 위한 수 
질 제어 및 관리방안 $\mathrm{I}\lrcorner$, 한국환경정책·평가연구원 (2010)), 이에 감 사드립니다.

\section{References}

1. Daughton, C. G., "Non-regulated Water Contaminants: Emerging Research,' Environmental Impact Assessment Review, 24, 711-732 (2004).

2. Palaniappan, M., Clearing the Waters: A Focus on Water Quality Solutions, United Nations Environment Programme, Division of Environmental Policy Implementation(2010).

3. Snyder, S. A., Vanderford, B. J., Drewes, J., Dickenson, E., Snyder, E., Bruce, G. M. and Pleus, R., State of Knowledge of Endocrine Disruptors and Pharmaceuticals in Drinking Water, Awwa Research Foundation(2008).

4. Massachusetts Department of Environmental Protection, http:// www.mass.gov/eea/agencies/massdep/toxics/sources/emergingcontaminants-fact-sheet-and-overview.html (accessed 31 July 2013).

5. Ministry of Environment, "National Water Environment Management Plan : A Masterplan of Water Quality Conservation at 4 Major River Basins (2006-2015),' (2006).

6. Nakdong River Watershed Management Comimttee, "Study on the Optimum Management of Micor-pollutants in Industrial Wastewater,' (2005).

7. Nakdong River Watershed Management Comimttee, "Risk assessment of the raw water,' (2006).

8. Nakdong River Watershed Management Comimttee, "Nakdong Basin-wide Monitoring of Potentially Hazardous Organics and Development of Prediction System,', (2008).

9. Nakdong River Watershed Management Comimttee, "Third Phase of Environmental Survey Project Master Plan at Nakdong River System,' (2012).

10. Ministry of Environment, "Guideline for the Operation of Drinking Water Quality Surveillance Substances,' (2012).

11. National Institute of Environmental Research, "A Study on Management of Unregulated Trace Hazardous Compounds in Drinking Water (II),' (2008).

12. Ministry of Environment, "Rules on the Management of Newly Detected Micro-hazardous Materials".

13. Office for Government Policy Coordination, The Ministry of Agriculture and Forestry, Ministry of Health \& Welfare, Ministry of Environment, Ministry of Maritime Affairs and Fisheries, Food \& Drug Administration. "A comprehensive plan for the management of antibiotic resistance (2008-2012)," (2007).

14. USGS, Toxic substances hydrology program, http://toxics.usgs. gov/index.html (accessed 31 July 2013).

15. USGS, Emerging contaminants in the environment, http://toxics.usgs.gov/regional/emc/index.html (accessed 31 July 2013).

16. Federal Office for the Environment (FOEN), Micropollutants - measures at wastewater treatment, http:/www.bafu.admin.ch/gewaesserschutz/03716/11218/11223/index.html?lang=en (accessed 31 July 2013).

17. Federal Office for the Environment (FOEN), "Faktenblatt: Projekt Strategie Micropoll - Modellstudie Ch.,' (2007).

18. Abegglen, C., "Eliminating Micropollutants: Wastewater Treatment Methods", Eawag News 67e/October (2009).

19. Ministry of Environment, "Development of the Investigatoin and
Management Measures of Hazaroud Substances for Increaseing the Number of Items Related to Protection of Human Health,' (2008).

20. Ministry of Agriculture \& Forestry, "Risk Information Manual on Agriculture and Food,' (2005).

21. National Institute of Environmental Research, "Study on Extended Authorization of Specific Toxic Substance and Establishment of the Effluent Standard (III),' (2004).

22. Ministry of Environment, "Detection of Some Pharmaceuticals Such as Antibiotics at Major River Water,' Press Release (21 March 2008).

23. National Institute of Environmental Research, "A Study on Management of Unregulated Trace Hazardous Compounds in Drinking Water (I),' (2012).

24. National Institute of Environmental Research, "A Study on the Estimation of the Discharge Loads of Perfluorinated Compounds (I), (2010).

25. Kim, S.-K., Im, J.-K., Kang, Y.-M., Jung, S.-Y., Kho, Y. L. and Zoh, K.-D., "Wastewater Treatment Plants (wwtps)-derived National Discharge Loads of Perfluorinated Compounds (pfcs)," J. Hazard. Mater., 201-202, 82(2012).

26. Carr, G. M. and Neary, J. P., Water quality for ecosystem and human health, UNEP/Earthprint(2008).

27. Phillips, P. J., Chalmers, A. T., Gray, J. L., Kolpin, D. W., Foreman, W. T. and Wall, G. R., "Combined Sewer Overflows: An Environmental Source of Hormones and Wastewater Micropollutants,' Environ. Sci. Technol. 46, 5336(2012).

28. Kumar, A., Williams, M., Woods, M., Kookana, R., Barber, L., Vajda, A., Doan, H., Gregg, A., Gonzago, D. and Bain, P., "Treated Effluent in the Aquatic Environment: Impact Assessment of Endocrine Disrupting Chemicals,' Water for a Healthy Country Flagship Report series (2012).

29. EAWAG, "Micropollutants in Water Resources: Prevention Assessment - Removal,' Media release on Eawag Info Day (23 June 2009).

30. Jenssen, B. M., "Endocrine-disrupting Chemicals and Climate Change: A Worst-case Combination for Arctic Marine Mammals and Seabirds?,' Environ. Health Perspect., 114, 76(2006).

31. Cho, Y. M. and Yoon, H. H., "The Vitalization Strategy of Water Reuse and Reclamation Industry,' Seoul Development Institute, (2009).

32. Tripoli, V. and Williams, C. D., "Emerging Contaminants: A Review with Policy Recommendations,' National Center for Conservation Science \& Policy(2008).

33. Joss, A., Siegrist, H. and Ternes, T., "Are We About to Upgrade Wastewater Treatment for Removing Organic Micropollutants?,' Water Sci. Technol., 57, 251(2008).

34. Yu, J.-J., "Management Strategy of Trace Hazardous Compounds in Nakdong River,' J. of KSEE, 31, 412(2009).

35. Yoo, C., Lee, T. Y., Kim, J., Moon, I., Jung, J. H., Han, C., Oh, J.-M. and Lee, I.-B., "Integrated Water Resource Management Through Water Reuse Network Design for Clean Production Technology: State of the Art,' Korean J. Chem. Eng., 24(4), 567 (2007).

36. Mohr, T. K., "Solvent Stabilizers,' Santa Clara Valley Water District, White Paper(2001).

37. Snyder, S. A., Westerhoff, P., Yoon, Y. and Sedlak, D. L., "Phar- 
maceuticals, Personal Care Products, and Endocrine Disruptors in Water: Implications for the Water Industry,' Environ. Eng. Sci., 20, 449(2003).

38. Yoo, H. I. and Ryu, S. K., "Removal of Trihalomethanes from Tap Water using Activated Carbon Fiber,' Korean Chem. Eng. Res.(HWAHAK KONGHAK), 50(1), 83(2012).

39. Lee, C.-H., Shun-hwa, L. and Jang, I.-H., "Occurrence of Prior- ity Pollutants in the Midstream of Nakdong River Basin,' $J$. of KSEE, 31, 401 (2009).

40. Ternes, T., Janex-Habibi, M., Knacker, T., Kreuzinger, N. and Siegrist, H., "Assessment of Technologies for the Removal of Pharmaceuticals and Personal Care Products in Sewage and Drinking Water Facilities to Improve the Indirect Potable Water Reuse,' Contract No. EVK1-CT-2000-00047(2004). 